\title{
|||||||||||||||||||||||||||||||||||||||||||||||||||||||||||||||||||.
}

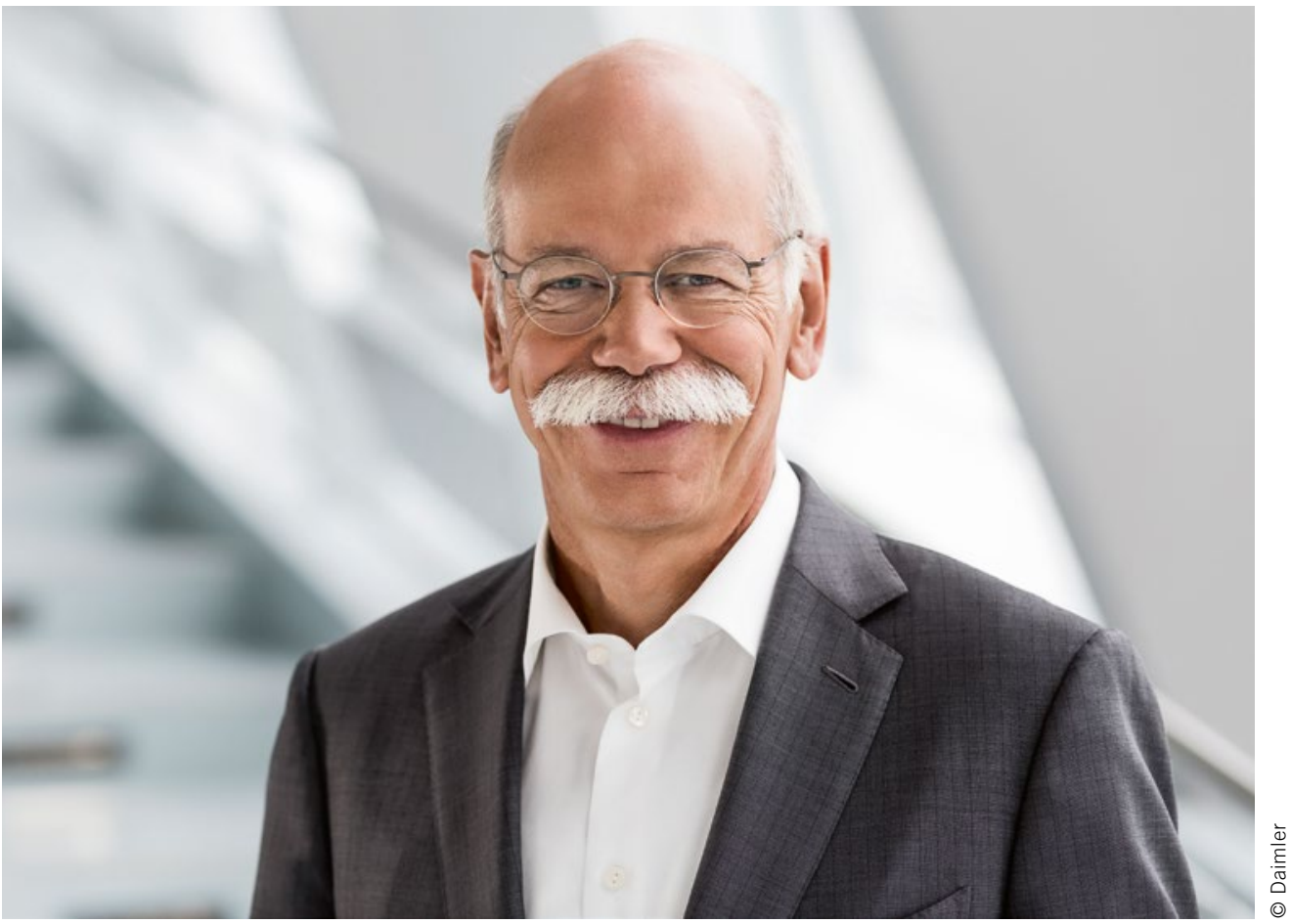

Dieter Zetsche

Vorsitzender des Vorstands der Daimler AG und Leiter

Mercedes-Benz Cars

\section{Von Institutionen und Ikonen}

Nur zwölf Jahre nachdem Carl Benz und Gottlieb Daimler 1886 das Auto erfunden haben, waren sie auch unter den Gründervätern des ersten Fachblatts für die Autoindustrie - damals noch unter dem Namen „Der Motorwagen“. Ihren Status als Referenz für Entwickler, Techniker und Ingenieure hat sich die ATZ bis heute erhalten. Deshalb: herzlichen Glückwunsch zum 120. Geburtstag! Es ist eine beeindruckende Leistung, große Tradition immer wieder neu mit Relevanz für Gegenwart und Zukunft zu verknüpfen. Das macht die ATZ zur Institution der Automobil-Fachpresse.

Autos, die wie die ATZ scheinbar die Zeit überdauern, werden irgendwann zum Klassiker. Ein paar Wenige schaffen es einen Schritt weiter: zur automobilen Ikone. Ikonen sind Autos, die bei Menschen in jeder Lebensphase starke Emotionen auslösen. Der VW Käfer gehört dazu - wie für viele andere auch mein erstes Auto. Ich würde außerdem den 911er von Porsche dazuzählen, den Mustang und den Wrangler. Und aus unserem Hause den Mercedes 300 SL und die G-Klasse. Aber wie genau wird ein Auto zur Ikone?

Erstens: Ikonen stehen für etwas - ohne Kompromisse. Sei es für ein bestimmtes Design, für Leistung oder ein spezielles Einsatzgebiet. Bis heute kennt jedes Kind die Form eines VW Käfer. Und die Geländegängigkeit der G-Klasse ist legendär.

Zweitens: Auto-Ikonen sind zeitlos. Sie laufen keinen Modetrends hinterher. Sie definieren einen Look - und bleiben ihm treu. Das gilt für die G-Klasse wie für die Coke-Flasche oder den Eames-Stuhl.

Drittens: Auto-Ikonen transportieren nicht nur Menschen, sondern auch Geschichten. Wie viele gute Geschichten gibt es rund um den 911er? Wer denkt beim Ford Mustang nicht auch an Steve McQueen?

Diese drei Faktoren helfen, aus einem Auto eine Ikone zu machen. Aber es reicht natürlich nicht, über Jahrzehnte Heldengeschichten aus vergangenen Zeiten zu erzählen und Rost fernzuhalten. Einen Klassiker zu bewahren bedeutet, ihn ständig weiterzuentwickeln. Man muss Geld und Ideen investieren, um die Geschichte weiterzuschreiben - und gleichzeitig möglichst nah am Original-Drehbuch zu bleiben.

Vor dieser Herausforderung standen wir zuletzt bei der Neuauflage der G-Klasse. Unser Geländewagen hat sich über vier Jahrzehnte immer weiterentwickelt. Aktueller Beleg: Es gibt nur drei Bauteile, die wir unverändert in die neue G-Klasse übernommen haben. Das Interieur ist neu, das Fahrgefühl auf der Straße besser denn je - und im Gelände ist die Legende noch stärker geworden. Trotzdem ist der neue G sofort als G zu erkennen. Das ist es, was eine Auto-Ikone lebendig hält.

Auf die ATZ übertragen bin ich überzeugt, dass es die Mischung aus relevanten Inhalten, journalistischem Handwerk und dem neugierigen Blick in die Zukunft ist, die ihr ihren Ausnahmestatus weiterhin sichern wird. Dafür alles Gute! 


\section{Das unübertroffene Molorla ger!}

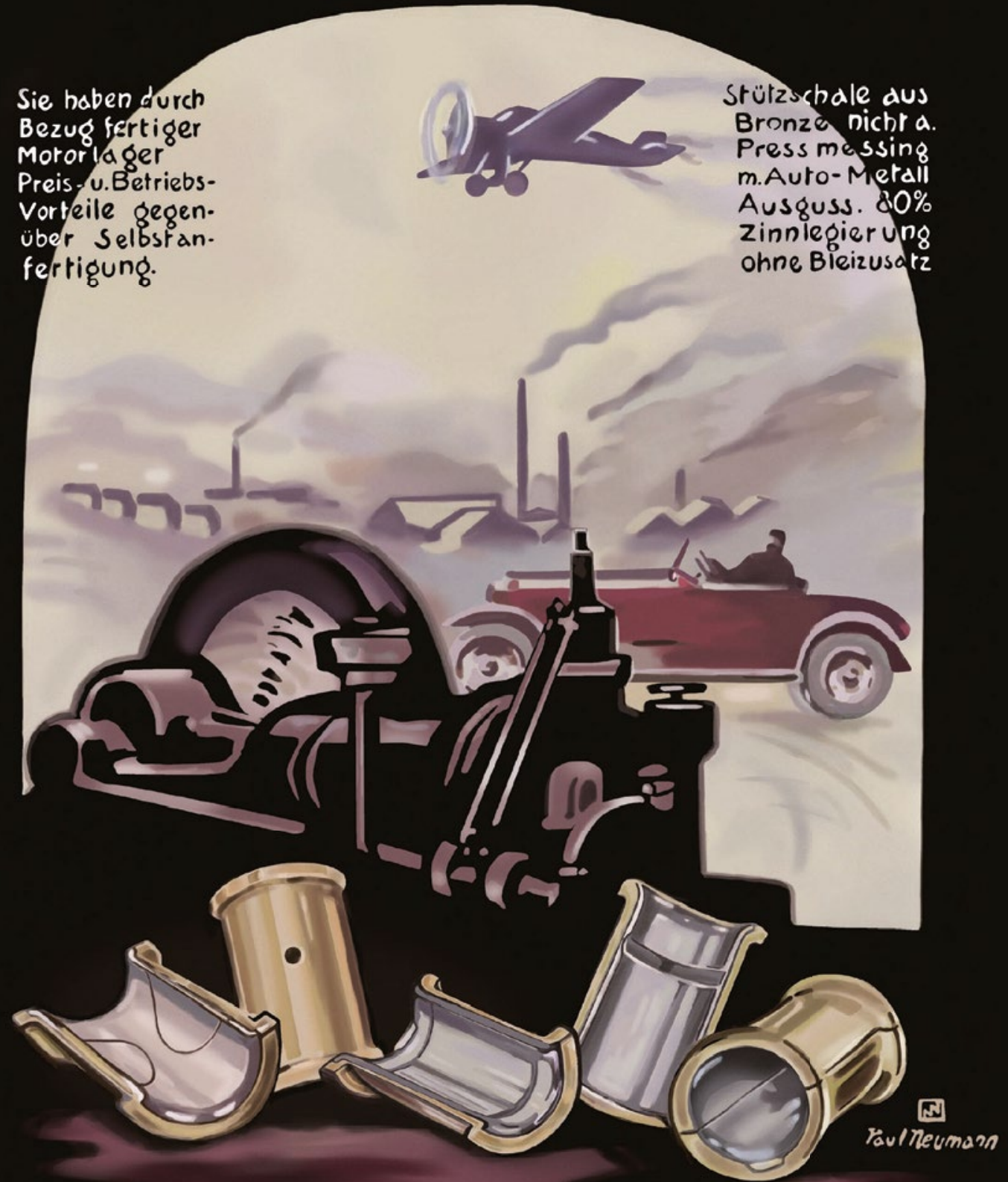

Kurbel-u.Plevelstangen-Lagerschalen

für Automobile, Lastwdgen, Boors morore

\section{GLYCO-METALLWERKE DAELEN \& LOOS SGHIERSTEIN ${ }^{\circ}$ Rt.}

\section{Leidenschaft für Technologie und Wissen - über Jahrzehnte Partner für die Industrie.}

